\title{
Damage behavior of honeycomb sandwich structure under low-energy impact
}

\author{
Jialin Cheng'1 , Zejin Li', Chaolin Shuai', Shuchang Long², Xiaohu Yaoª \\ 1 Chengdu Aircraft Industrial (Group) Co., Ltd, PR China \\ 2 Department of Engineering Mechanics, School of Civil Engineering and Transportation, \\ South China University of Technology, Guangzhou, 510640, P. R. China
}

\begin{abstract}
Honeycomb sandwich structure is widely used in aircrafts and ships to absorb impact energy. Damage caused by low-energy impact is difficult to investigate, but will significantly reduce the strength of the sandwich structure. This paper presented a systematical experimental study on the damage behavior of honeycomb sandwich structure under different configurations. Drop weight tests were carried out to investigate the effect of impact energy, core material and face plate structure on the dynamic response of sandwich plate. Delamination regions were obtained through ultrasonic scanning. Conclusions were made that the damage behavior of the face plate was similar with composite laminates while the energy absorption capacity was related to the parameters of the honeycomb core and the mismatch angle of the face plate.
\end{abstract}

\section{Introduction}

A sandwich structure consists of three parts: two stiff face plates and a light weighted core. Since the structure can absorb a large amount of energy with small deformation, it is widely used in aircrafts, ships and other structure that may suffer impact loads. For a sandwich structure, the damage caused by a low-energy impact is difficult to obtained, but will significantly reduce the strength of the structure, especially the interface strength. As a result, it is important to summarize the damage regulation of sandwich structure under low-energy impact.

The sandwich structure studied in this paper was called honeycomb sandwich structure. The face plate was stacked by unidirectional composite laminates, while the core was composed by honeycomb structure made of Nomex. Composite laminates were widely used in aircrafts because of the high strength-weight ratio. Honeycomb structure was stable and light weighted, furthermore it can absorb a large amount of energy with the buckling of honeycomb cells. The combination of two materials made the structure stiff and light. However, the delamination within face plate, the debonding between face plate and core, and the crush of honeycomb may seriously reduce the strength of the whole structure.

Studies were carried out all over the world on the impact response of sandwich structure. Mines [1] carried out low-velocity impact tests on sandwich panels composed by a specific series of material and geometry. Results have shown that the density of the core influenced the progression of failure and that higher impact velocities increased the energy absorption capabilities of the panels. Dharmasena [2] performed explosive tests on honeycomb core sandwich panels. The sandwich structure was found suffered significantly smaller back face deflections than solid plates of identical mass. Schubel [3] compared the low velocity impact test with quasi-static test on composite sandwich structure. It was proved that results of the two tests were similar except the localized damage while quasi-static test was easier to perform and analyze. Zhao [4] used the viscoelastic split bars and the two-strain measurement method to measure the crushing behavior of honeycombs. The experimental results show that only the out-of-plane crushing behavior was affected by the loading rate. In the study of Gustin [5], impact compression after impact, and tensile stiffness properties of carbon fiber and Kevlar combination sandwich composites were investigated. They found that the addition of Kevlar and hybrid to the face sheet improved the maximum absorbed energy of the structure. Herup [6] characterized the damage initiation of Nomex honeycomb sandwich panels as a function of facesheet thickness and loading rate. Liu [7] conducted tensile, stabilized compressive and step-by-step compressive tests to study the material properties and mechanical response of the Nomex honeycomb core under transverse loading. Anderson [8] presented the results of experimental investigation on impact response of sandwich structure with honeycomb core and foam core. The extent of damage within the structure was provided by the correlation of the residual indentation and cross-sectional views.

In this paper, a systematical experimental study was carried out on the damage behavior of honeycomb

\footnotetext{
a Corresponding author: yaoxh@scut.edu.cn
} 
sandwich structure under low-energy impact. The effect of impact energy, core material and face plate stacking sequence were investigated by three groups of tests. The dynamic response was recorded as impact force curves, and the delamination region was obtained through $\mathrm{C}$-scan. In conclusion, the damage regulation of sandwich structure was summarized and some future works were listed.

\section{Material and Method}

Drop weight tests were carried out to investigate the damage behavior of honeycomb sandwich structures under impact loads. The test procedure was based on ASTM-D7766. Specimens were cut into plates with a size of $150 \mathrm{~mm} \times 100 \mathrm{~mm}$. The face plates of the sandwich plate were stacked by $\mathrm{T} 700 / 3234$ unidirectional carbon/epoxy composite while the honeycomb core was made of Nomex. The structure of the specimen was presented in Figure 1. The mechanical parameters of composite layers were listed in Table 1.
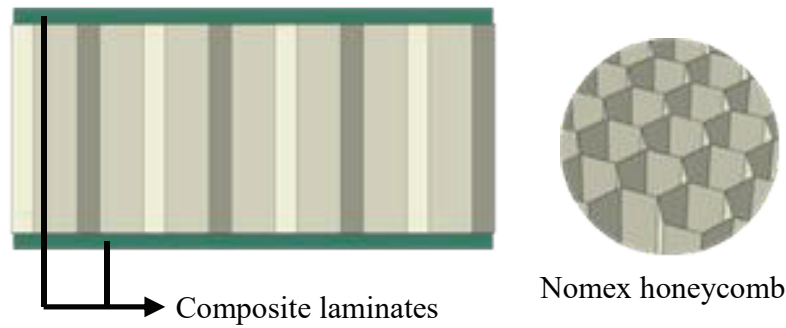

Nomex honeycomb

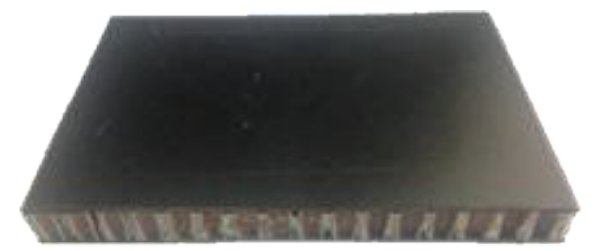

Figure 1. Structure of honeycomb sandwich plates

Table 1. Mechanical parameters of T700/3234 UD composite

\begin{tabular}{l|l|l}
\hline \multicolumn{2}{l|}{ Density } & $1700 \mathrm{~kg} / \mathrm{m}^{3}$ \\
\hline \multirow{5}{*}{ Intra-laminar } & $\begin{array}{l}\text { Elastic } \\
\text { properties }\end{array}$ & $\begin{array}{l}E_{l}=110 \mathrm{GPa}, E_{2}=7.8 \mathrm{GPa}, \\
v_{12}=0.32, G_{12}=G_{13}=G_{23}=4 \mathrm{GPa}\end{array}$ \\
\cline { 2 - 3 } Strength & $\begin{array}{l}X^{T}=2093 \mathrm{MPa}, X^{C}=870 \mathrm{MPa}, \\
Y^{T}=50 \mathrm{MPa}, Y^{C}=198 \mathrm{MPa}, \\
S^{L}=104 \mathrm{MPa}\end{array}$ \\
\cline { 2 - 3 } Inter-laminar & $\begin{array}{l}\text { Fracture } \\
\text { energy }\end{array}$ & $\begin{array}{l}G_{f t}=G_{f c}=10 \mathrm{~N} / \mathrm{mm}, \\
G_{m t}=G_{m c}=1 \mathrm{~N} / \mathrm{mm}\end{array}$ \\
\hline & $\begin{array}{l}\text { Elastic } \\
\text { properties }\end{array}$ & $K_{n}=K_{s}=K_{l}=850 \mathrm{MPa}$ \\
\cline { 2 - 3 } & Strength & $\begin{array}{l}T_{n}=3.3 \mathrm{MPa} \\
T_{s}=T_{t}=7 \mathrm{MPa}\end{array}$ \\
\cline { 2 - 3 } & $\begin{array}{l}\text { Fracture } \\
\text { energy }\end{array}$ & $\begin{array}{l}G_{n}=0.306 \mathrm{~N} / \mathrm{mm} \\
G_{s}=G_{l}=0.632 \mathrm{~N} / \mathrm{mm}\end{array}$ \\
\hline
\end{tabular}

The drop weight machine used in the tests was InstronDynatup $9250 \mathrm{HV}$ made in USA. The specimen was clipped on a rigid supporting structure with a rectangular cut of $125 \mathrm{~mm} \times 75 \mathrm{~mm}$ in the center. The center of the specimen was impacted by a hemisphere punch head weighted $18.89 \mathrm{~kg}$ with a diameter of $16 \mathrm{~mm}$. The impact force and the displacement of the punch were recorded during the test procedure. After the drop weight tests, specimens with visible damage were examined by C-scan. The SAM-300 ultrasonic scanning microscope made in Germany was used in the nondestructive tests.

\section{Result and discussion}

The test results were divided into three groups in order to reveal the damage regular of honeycomb sandwich structures under different configurations. The damage behavior was characterized by the visible failure of material, the dynamic response of specimen and the delamination area inside the plate.

\subsection{Effect of impact energy}

Three specimens with the same components were tested under different impact energy. The stacking sequence of face plates is [45/-45/90/0/0/90/-45/45], which represents that the fiber direction in top layer of the face plate is $45^{\circ}$, while the second layer is $-45^{\circ}$, and so on. Fiber direction is defined as the extension direction of carbon fibers during the forming process. Curves of impact force versus time and displacement were plotted in Figure 2. All curves share the same trend with two peak values. The first peak value represented the ultimate load of the top face plate. After the penetration of the top plate, the honeycomb core began to bear the main load. Since the core material was much weaker than the face plate, the load level of this stage was much lower than the peak value. When the core was crushed by the punch head, the bottom face plate began to bear the main load, shown as the second peak value. With the load level of $17.21 \mathrm{~J}$, the impact energy was absorbed completely by the damage of top face plate and the crush of core. As a result, the second peak value was very small since the bottom face plate did not bear the impact load.

The area enclosed by the curve of impact force versus displacement equals to the energy absorbed by the structure. Although the strength of the core material was low, the buckling of the honeycomb cells contributed a large displacement in the vertical direction. As a result, the honeycomb core absorbed a large amount of impact energy and prevented the bottom face plate from any damage and failure.

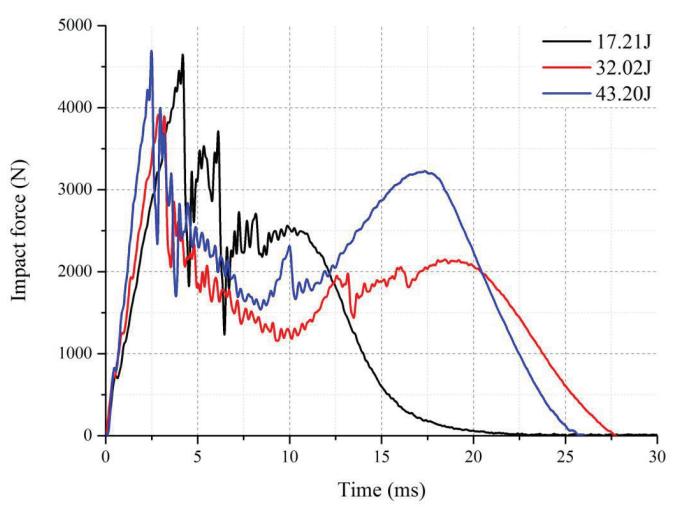

(a) Impact force versus time curves 


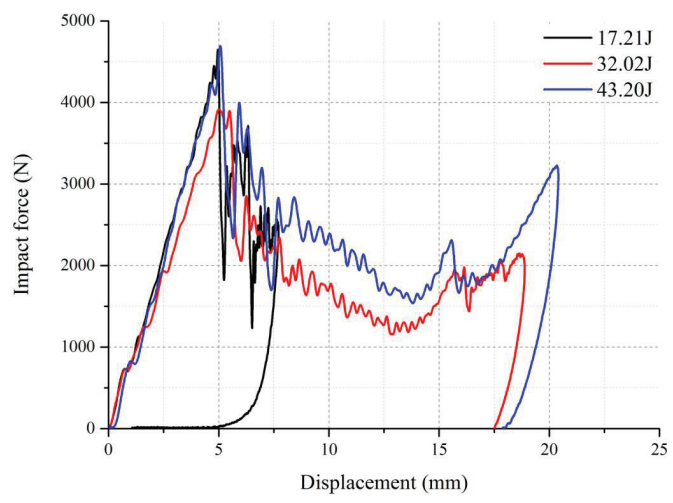

(b) Impact force versus displacement

Figure 2. Curves of specimens under different impact energy

The C-scan results of the three specimens were shown in Table 2. The region in white represented the delamination area. Delamination distributed around the impact zone and along the fiber direction of the sub layer below the interface. This phenomenon was similar with the regulation of composite laminates [9]. On the contrary, the debonding area between top face plate and core was found along the sub layer above the interface.

Table 2. Delamination area of top face plate under different impact energy

\begin{tabular}{|c|c|c|c|}
\hline $\begin{array}{l}\text { Impact } \\
\text { Energy }\end{array}$ & $17.21 \mathrm{~J}$ & $32.02 \mathrm{~J}$ & $43.20 \mathrm{~J}$ \\
\hline $\begin{array}{l}\text { Interface } \\
\text { I :-45/90 }\end{array}$ & & & \\
\hline $\begin{array}{l}\text { Interface } \\
\text { II :90/0 }\end{array}$ & & & \\
\hline $\begin{array}{l}\text { Interface } \\
\text { III :45/core }\end{array}$ & & & \\
\hline
\end{tabular}

\subsection{Effect of honeycomb core}

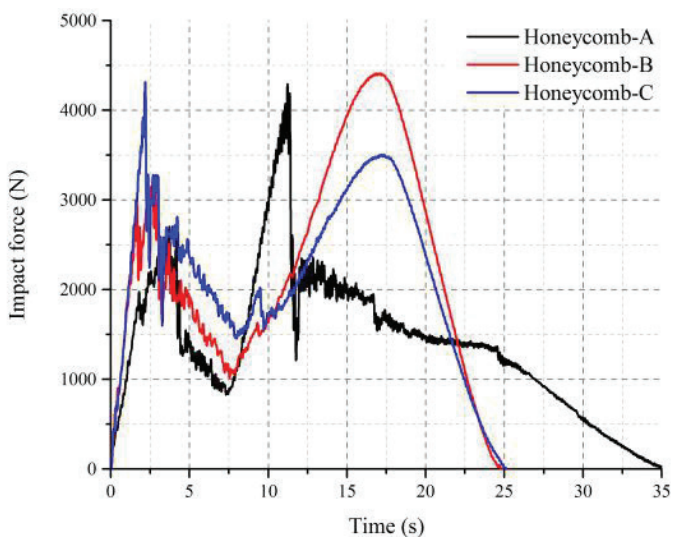

(a) Impact force versus time curves

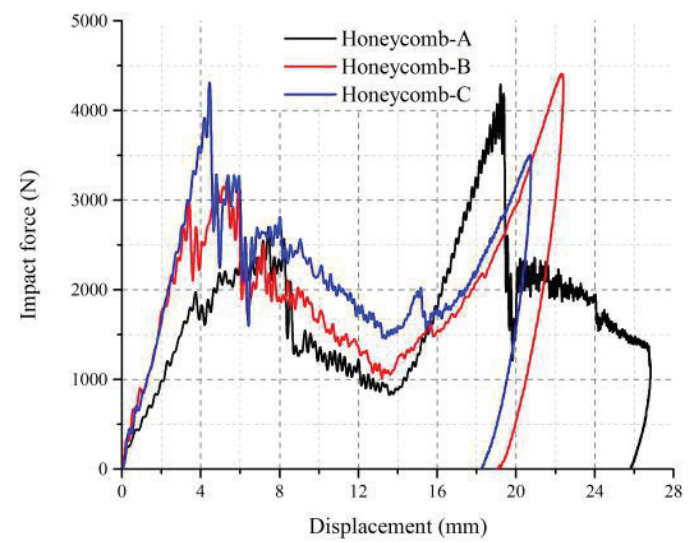

(b) Impact force versus displacement

Figure 3. Curves of specimens with different core parameters

Three specimens with different core parameters were impact under 40J. The cores, made of Nomex honeycomb, were different in cell length (L) and density $(\rho)$. Detailed description can be found in Table 3 .

Table 3. Delamination area of top face plate with different core parameters

\begin{tabular}{|c|c|c|c|c|}
\hline $\begin{array}{l}\text { Honeyco } \\
\text { mb type }\end{array}$ & A & $\begin{array}{l}\mathrm{L}=2.75 \mathrm{~mm} \\
\rho=48 \mathrm{~kg} / \mathrm{m}^{3}\end{array}$ & \begin{tabular}{l|l} 
& $\begin{array}{l}\mathrm{L}=2.75 \mathrm{~mm} \\
\rho=80 \mathrm{~kg} / \mathrm{m}^{3}\end{array}$ \\
\end{tabular} & C $\begin{array}{l}\mathrm{L}=1.83 \mathrm{~mm} \\
\rho=80 \mathrm{~kg} / \mathrm{m}^{3}\end{array}$ \\
\hline $\begin{array}{c}\text { Interface } \\
\text { I }: 45 / 90\end{array}$ & & & & \\
\hline $\begin{array}{l}\text { Interface } \\
\text { II }: 45 / 0\end{array}$ & & & & \\
\hline $\begin{array}{c}\text { Interface } \\
\text { III : } \\
-45 / \text { core }\end{array}$ & & & & \\
\hline
\end{tabular}

According to the curves in Figure 3, the slops of rising steps for B and C were almost the same, which means honeycomb core with the same density share the same stiffness. As for specimen A, whose core density was much lower, the slope of the curves was low while the first peak value reduced. In the impact process of specimen A, after the damage of top plate and the crush of core, there was a mount of impact energy remains, which leads to the damage of bottom plate. Conclusion can be made that a weak core material can reduce the damage of top face plate but will lead to serious failure of bottom face plate.

Delamination areas of the three specimens were shown in Table 3 . The regulation was similar with the first group of tests, especially the shape of debonding area between top face plate and core.

\subsection{Effect of face plate stacking sequence}

The stacking sequence of composite laminates was proved to affect the delamination area between sub layers. 
In order to study the effect of face plate structure on the sandwich plate, two specimens with different stacking sequence were tested under $30 \mathrm{~J}$.

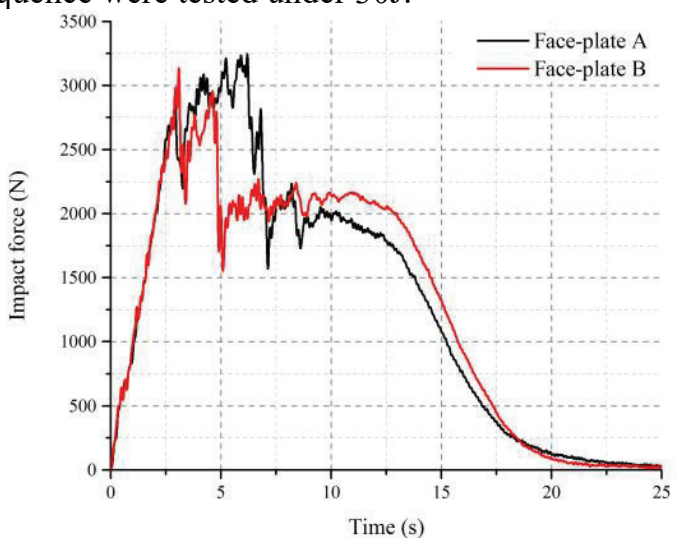

(a) Impact force versus time curves

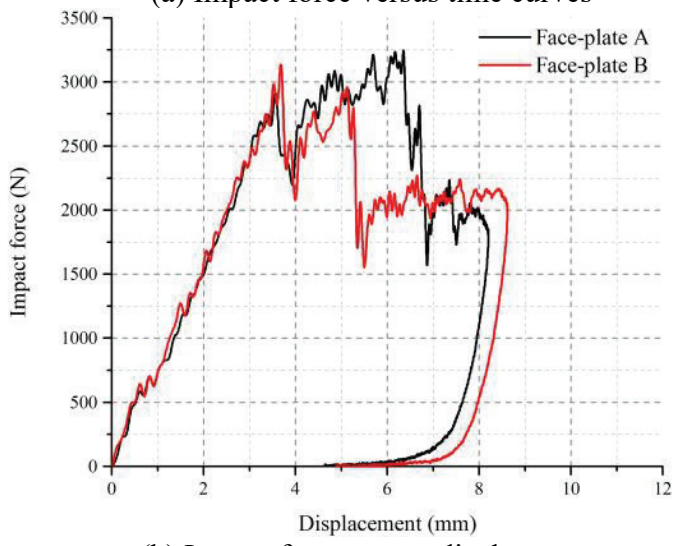

(b) Impact force versus displacement

Figure 4. Curves of specimens with different core parameters

Table 4. Delamination area of top face plate with different core parameters

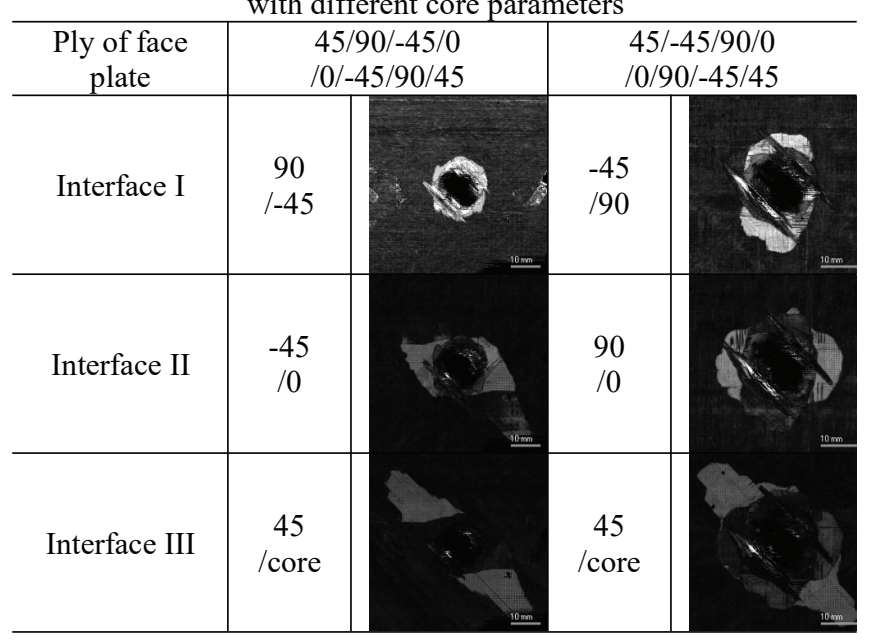

The dynamic responses of the two specimens were almost the same, except the time of the load drop. The sudden change of the impact force can be regarded as the characterization of the penetration. Later penetration will lead to more damage in top face plate, and at last improve the energy absorption capacity of sandwich structure. As can be seen, the mismatch angle of the stacking sequence of specimen A was smaller than that of specimen B. It is proved that a face plate with big mismatch angles was easy to be penetrated. Delamination areas were also presented in Table 4. The shape of debonding zone was controlled by the ply angle as discussed in above sections.

\section{Conclusion}

This paper presented the study on the damage behavior of honeycomb sandwich structure under low energy impact. Damage of the structure under different configurations was characterized and some regulations were summarized. Conclusions can be made as follow:

(1) The curves of impact force versus time and displacement can be divided into three steps. At first, the top face plate bears the main load. After the ultimate strength is met, the top face was penetrated and the core begins to bear main load. When the honeycomb was completely crushed, the major impact load was applied on the bottom face plate.

(2) A weak core can reduce the damage of the top face plate but will lead to serious failure of the bottom face plate.

(3) A face plate with big mismatch angles is easy to be penetrated. Reducing the mismatch angles of the face plate can increase the energy absorption capacity of the whole structure.

(4) The delamination area within a face plate share the same regulation of composite laminates. While the debonding area between top face plate and core was found along the fiber direction of the sub layer above the interface.

Future works will focus on numerical studies of honeycomb sandwich structure. Proper institutive model will be chosen for the Nomex honeycomb material. The damage process of face plate and the crush of core will be discussed in detail. Residual strength of sandwich structure will also be considered in follow-up works.

\section{Acknowledgement}

The financial sponsorship and support from the Natural Science Foundation of China (11472110, 11372113), the Fundamental Research Funds for the Central Universities (2014ZG0033), and New Century Excellent Talents(NCET-13-0218). This paper is also supported by the opening project of State Key Laboratory of Explosion Science and Technology (Beijing Institute of Technology) (KFJJ14-2M).

\section{References}

1. Mines R A W, Worrall C M, Gibson A G. Low velocity perforation behavior of polymer composite sandwich panels [J]. International Journal of Impact Engineering, 21 (1998).

2. Dharmasena K P, Wadley H N G, Xue Z, et al. Mechanical response of metallic honeycomb sandwich panel structures to high-intensity dynamic loading $[\mathrm{J}]$. International Journal of Impact Engineering, 35 (2008). 
3. Schubel P M, Luo J J, Daniel I M. Low velocity impact behavior of composite sandwich panels [J]. Composites Part A Applied Science \& Manufacturing, 36 (2005).

4. Zhao H, Gary G. Crushing behavior of aluminum honeycombs under impact loading [J]. International Journal of Impact Engineering, 21 (1998).

5. Gustin J, Joneson A, Mahinfalah M, et al. Low velocity impact of combination Kevlar/carbon fiber sandwich composites [J]. Composite Structures, 69 (2005).

6. Herup E J, Palazotto A N. Low-velocity impact damage initiation in graphite/epoxy/Nomex honeycomb-sandwich plates [J]. Composites Science \& Technology, 12 (2013).

7. Liu L, Wang H, Guan Z. Experimental and numerical study on the mechanical response Of Nomex honeycomb core under transverse loading [J]. Composite Structures, 121 (2015).

8. Anderson T, Madenci E. Experimental investigation of low-velocity impact characteristics of sandwich composites [J]. Composite Structures, 50 (2000).

9. Long $\mathrm{S}$, Yao X, Zhang X. Delamination prediction in composite laminates under low-velocity impact [J]. Composite Structures, 132 (2015). 